\title{
Phase Changes in Radiation Protection Composite Materials Based on Bismuth Oxide
}

\author{
S. Yashkina $\left.{ }^{(}\right)$, V. Doroganov, E. Evtushenko, O. Gavshina, \\ and E. Sysa \\ Department of Technology of Glass and Ceramics, Belgorod State Technological \\ University named after V.G. Shukhov, Belgorod, Russia \\ yashkina_asp@mail.ru
}

\begin{abstract}
XRF method was used to study the mineralogical compounds of the radiation protection ceramic materials based on a high-alumina binder and a "heavy" aggregate, bismuth oxide. The content of $\mathrm{Bi}_{2} \mathrm{O}_{3}$ in the test samples was kept in the range of 38.5-75 wt\%. Along with the bismuth oxide, the aggregate was aluminum oxide $\left(\mathrm{Al}_{2} \mathrm{O}_{3}\right)$. The binder synthesis followed the principle of obtaining ceramic concretes based on artificial ceramic binders (ACB).

The paper establishes the specifics of sintering of the composites under study, fired under different temperatures.
\end{abstract}

Keywords: Bismuth oxide $\cdot$ Artificial ceramic binders $\cdot$ X-ray fluorescence $\cdot$ Radiation protection ceramic composites

\section{Introduction}

Bismuth oxide is a widely used bismuth compound due to its chemical stability, low toxicity, and its unique physical and chemical properties (Gulbin et al. 2014). Its sufficiently high density $\left(8.9 \mathrm{~g} / \mathrm{cm}^{3}\right)$ allows to use it in the synthesis of "heavy" materials employed in the protection from gamma rays. As it is known, in this case, the leading role in characterizing the protective properties is played by the density of the material. In the way of exercising high structural properties, the most efficient were the ceramic matrices (Correya et al. 2018).

This paper studies the phase transformations of the radiation protection materials based on the high-alumina ACBs, bismuth oxide, and aluminum oxide sintered at different temperatures.

\section{Methods and Approaches}

Obtaining the artificial ceramic binder (ACB) was carried out through the technique of wet grinding in a periodic action ball mill with a stepwise loading of material. This principle of obtaining ceramic concretes allows to obtain matrices with the desired phase composition, improved physical and mathematical properties and ensures the broad opportunities for using various aggregates. 
The suspension based on high-alumina grog possesses the thixotropic dilatant flow (the destruction of the initial thixotropic structure and the following dilatant formation of structure). The bismuth oxide powder used as aggregate represents spherical particles sized no more than $35 \mu \mathrm{m}$.

The source materials were mixed in the proportions presented in Table 1 . Then, the technique of static pressing was used with the specific pressure of $100 \mathrm{MPa}$ to form the bar. After drying, the samples were subjected to burning within the interval of $200^{\circ}$ to $1000{ }^{\circ} \mathrm{C}$ with holding at the maximum temperature for one hour.

Table 1. Compositions of radiation protection materials

\begin{tabular}{l|l|l|l}
\hline \multirow{2}{*}{ Number of the compound } & \multicolumn{3}{|l}{ Content, wt\% } \\
\cline { 2 - 4 } & $\mathrm{ACB}$ & $\mathrm{Al}_{2} \mathrm{O}_{3}$ & $\mathrm{Bi}_{2} \mathrm{O}_{3}$ \\
\hline 1 & 38.5 & 23.0 & 38.5 \\
\hline 2 & 19.0 & 23.0 & 58.0 \\
\hline 3 & - & 25.0 & 75.0 \\
\hline
\end{tabular}

The X-ray fluorescence analysis was performed using the DRON-3 diffractometer. XRD patterns were recorded using the $\mathrm{CuK} \alpha$ radiation (Ni filter); tube voltage: $20 \mathrm{kV}$; tube anode current: $20 \mathrm{~mA}$; measuring range: 10000-4000 PPS; detector turn rate: $2.4 \mathrm{rpm}$; elevation angle: 10. The JCPDF database was used for identification.

\section{Results and Discussion}

The analysis of the transformations of the samples with the admixture $\mathrm{Bi}_{2} \mathrm{O}_{3}$ at varied temperatures (Figs. 1, 2 and 3) indicates that heating within the interval of $100-500{ }^{\circ} \mathrm{C}$, all compounds are mineralogically constant and exhibit phases of mullite, corundum, and $\mathrm{Bi}_{2} \mathrm{O}_{3}$.

When increasing the burning temperature to $600{ }^{\circ} \mathrm{C}$, starts the formation of bismuth silicates $2 \mathrm{Bi}_{2} \mathrm{O}_{3} \cdot 3 \mathrm{SiO}_{2}$ and $12 \mathrm{Bi}_{2} \mathrm{O}_{3} \cdot 2 \mathrm{SiO}_{2}$. Further increase of the burning temperature to $700{ }^{\circ} \mathrm{C}$ leads to a more intensive formation of bismuth silicates, indicated by the increase in the intensity of reflections for these compounds. In the process, the entire $\mathrm{Bi}_{2} \mathrm{O}_{3}$ turns into silicates, while the interplanar reflections of bismuth oxide totally disappear. There occurs a sharp decrease in the intensity of mullite peaks, while in the composition No. 3 this compound is totally absent.

When the temperature is increased up to $800{ }^{\circ} \mathrm{C}$ and further, all compositions display further formation of bismuth silicates, and in the compositions No. 2-3 there were identified two phases of $\alpha-\mathrm{Al}_{2} \mathrm{O}_{3}$ и $12 \mathrm{Bi}_{2} \mathrm{O}_{3} \cdot 2 \mathrm{SiO}_{2}$, while in the composition No. 1 , in addition to the indicated two, there also forms $2 \mathrm{Bi}_{2} \mathrm{O}_{3} \cdot 3 \mathrm{SiO}_{2}$ (Figs. 1, 2 and 3). 


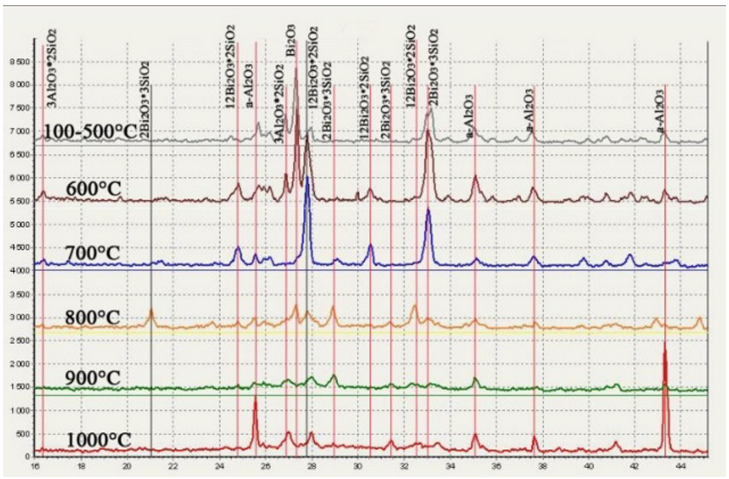

Fig. 1. X-ray patterns of the samples of the composition of radiation protection composites No. 1

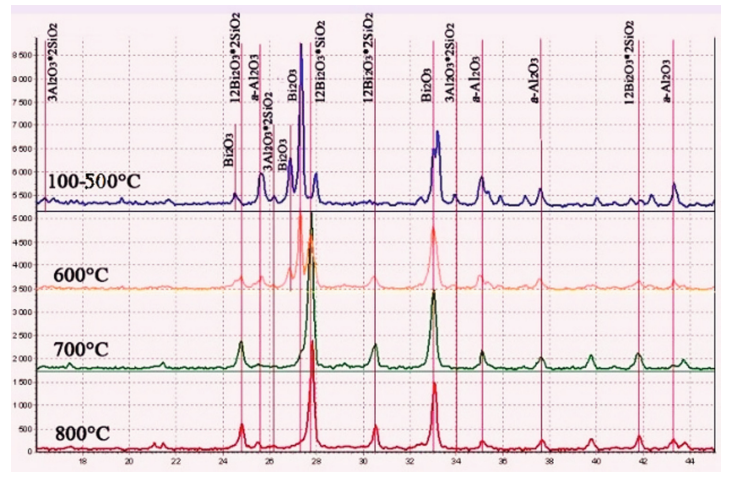

Fig. 2. X-ray patterns of the samples of the composition of radiation protection composites No. 2

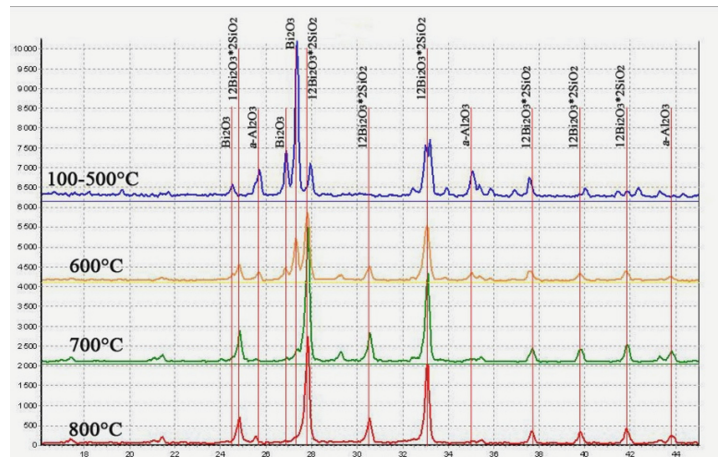

Fig. 3. X-ray patterns of the samples of the composition of radiation protection composites No. 3 
It is possible to assume that compositions No. 1-2 show the formation of bismuth silicates as a result of mullite decomposition and binding of $\mathrm{SiO}_{2}$ into the bismuth silicates, while in the composition No. 3 the silicates form due to the interaction of $\mathrm{Bi}_{2} \mathrm{O}_{3}$ and the nanosilica introduced as binder.

\section{Conclusions}

This paper studied the mineralogical compounds of the radiation protection ceramic materials based on a high-alumina ACB and bismuth oxide. It was identified that the higher the content of $\mathrm{Bi}_{2} \mathrm{O}_{3}$ in the source composition, the more intensive is the process of mullite decomposition. This way, at the content of $\mathrm{Bi}_{2} \mathrm{O}_{3} 38,5 \%$, mullite perseveres up to the temperature of $900{ }^{\circ} \mathrm{C}$, and if bismuth oxide is increased to $58 \%$, mullite disintegrates completely at the temperature of $700{ }^{\circ} \mathrm{C}$, which is $200{ }^{\circ} \mathrm{C}$ lower than the previous composition.

Acknowledgement. The work is realized in the framework of the Program of Flagship University development on the base of the Belgorod State Technological University named after V.G. Shukhov, using the equipment of High Technology Center at BSTU named after V.G. Shukhov.

\section{References}

Correya AA, Mathew S, Nampoori VPN, Mujeeb A (2018) Structural and optical characterization of hexagonal nanocrystalline bismuth-bismuth oxide core-shell structures synthesized at low temperature. Optik 175:930-935

Gulbin VN, Kolpakov NS, Polivkin VV (2014) Radio - i radiatcionno-zashchitnye kompozitcionnye materialy $\mathrm{s}$ nanostrukturnymi napolniteliami [Radiation protection composite materials with nanostructure aggregates]. VSTU Bull 23:43-51

Open Access This chapter is licensed under the terms of the Creative Commons Attribution 4.0 International License (http://creativecommons.org/licenses/by/4.0/), which permits use, sharing, adaptation, distribution and reproduction in any medium or format, as long as you give appropriate credit to the original author(s) and the source, provide a link to the Creative Commons license and indicate if changes were made.

The images or other third party material in this chapter are included in the chapter's Creative Commons license, unless indicated otherwise in a credit line to the material. If material is not included in the chapter's Creative Commons license and your intended use is not permitted by statutory regulation or exceeds the permitted use, you will need to obtain permission directly from the copyright holder.

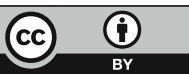

